\title{
Quality indicators of telemedical care offshore-a scoping review
}

\author{
Michael Hellfritz , Alexander Waschkau and Jost Steinhäuser
}

\begin{abstract}
Background: Offshore industries operate all around the world in diverse and remote environments. The use of telemedicine to ensure up-to-date medical care for thousands of people offshore has been common practice for decades. Thus, in this setting, extensive experiences with this type of health care delivery have already been gathered, while in other settings this is just beginning. However, the quality of telemedical care on offshore installations is rarely reported yet. The objective of this review was to explore published literature with regards to the following questions: Have any Quality Indicators (QIs) been published for measuring the quality of telemedical care on offshore installations or are there identifiable items that could be used as such Qls?

Methods: We conducted a comprehensive Scoping Review (PRISMA-SCR) of the published literature using the databases MEDLINE, Cochrane Library, Web of Science (Core Collection), and Google Scholar. Search results were read and Qls or findings from which Qls could be derived were classified according to the dimensions of quality established by Donabedian (structure, process, or outcome QIs).

Results: The search returned 10,236 non-recurring articles, 45 of which were full-text screened and 15 of which were included in this review. Types of publications were heterogenous. No Qls for the quality of telemedical care offshore have been published yet. Findings that could be the basis for Qls focused on structure quality (11 Qls) followed by process quality (11 Qls), while outcome quality was less common (1 QI).
\end{abstract}

Conclusion: Currently, although years of experience with telemedical care on offshore installations exist, there is a paucity of research on a solid data base regarding the quality of telemedical care offshore. The authors derived a list of 24 possible Qls from the findings of the publications for further validation. This could be the basis for implementation and definition of QIs in this and in similar remote settings.

Keywords: Offshore, Oil and gas industry, Offshore wind energy, Telemedicine, Medical care, Quality, Quality Indicator, Scoping review

\section{Background}

Offshore wind and offshore oil and gas industries operate all around the world. It is estimated that, in 2008, at any particular time, 15-28,000 people lived and worked offshore in and on the entire North Sea alone [1]. The United Kingdom (UK) Oil and Gas Industry Association counted almost 50,000 workers travelling offshore in the

*Correspondence: michael.hellfritz@student.uni-luebeck.de Institute of Family Medicine, University Medical Center SchleswigHolstein, Campus Lübeck, Ratzeburger Allee 160, 23562 Lübeck, Germany
UK sector in 2017, with over 23,000 of them spending at least 100 nights offshore [2].

Offshore installations can vary greatly in size, manning, and function. While some oil drilling rigs permanently accommodate up to several hundred people, offshore wind structures may only be visited irregularly by small teams of three people. Legal requirements for the provision of medical care in the offshore oil and gas industry vary internationally $[3,4]$. Up to now, the much younger offshore wind industry has relied heavily on the selfimposed standards of the oil and gas industry. 
According to industries Health, Safety \& Environment standards, a medical professional-usually called 'Medic' - should be stationed at any major installation. 'Medic' generally refers to a medical professional (e.g. paramedic, emergency medical technician, nurse, medical doctor) with experience in emergency medical care and with advanced life support skills $[3,5,6]$.

To support the provision of medical care offshore, telemedicine has been common practice for decades [6]. Initially referring to telephone and radio communication, nowadays telemedical solutions often include live videoconferencing, transmission of advanced subjective and objective medical information and a coordinated specialized medical team onshore [1, 6, 7].

Epidemiology patterns of offshore medical emergencies and reasons for evacuations have changed over the past five decades. In the 1970s, substantially more injuries than illnesses occurred offshore. In 1985, out of 743 consultations on offshore installations dealt with by the medical support doctors onshore, $29 \%$ were successfully treated only with advice over radio to the offshore medical personnel. In the $1990 \mathrm{~s}$, illnesses made up more than $55 \%$ of the reasons for evacuation, with musculoskeletal, dental, and respiratory illnesses being the most common, and cardiovascular, skin, mental, and genitourinary illnesses being the least common reasons for evacuation. Most commonly evacuated injuries were sprains, strains, and fractures [3].

Thus, in offshore settings, extensive experiences with telemedical care have been gathered in thousands of consultations over decades [8]. However, although existing literature partly covers aspects of quality, there is only a very limited number of publications focusing on the quality of telemedical care on offshore installations.

The use of telemedicine in other areas has increased over the past years [9]. Organizational issues have not been adequately examined yet [10]. Telemedical care projects in other settings, e.g., rural and remote areas, could benefit from the experiences and research findings of offshore telemedical care.

Donabedian established a comprehensive approach for the assessment and evaluation of the quality of medical care, introducing three dimensions of quality: structure, process, and outcome quality. Structure quality describes the material, personnel, and administrative conditions that medical care is delivered in. Process quality maps the immediate interaction between the physician, the medical assistants, the administrators, and the patient. And outcome quality describes the outcome of the medical condition of the patient. Analyzing these dimensions of quality of care can result in measurable quality indicators (QIs) [11]. Such QIs are essential for documenting and improving the quality of medical care [12].
The objective of the present study was to explore the published literature with regards to the following questions: Which QIs describing the quality of telemedical care on offshore structures have been published?Are there any items in existing publications that could be used as a basis for such QIs?

\section{Methods}

On August 11th, 2021, a comprehensive Scoping Review was carried out, using the databases and meta-databases MEDLINE, Cochrane Library, and Web of Science (Core Collection). It followed the guidelines of the PRISMA Extensions for Scoping Reviews (PRISMA-ScR) [13] (see Additional file 1), and was not registered prior to the search or publication. It was supplemented by a search for grey literature with Google Scholar.

\section{Search strategy}

To ensure a maximum spectrum of relevant results, we developed a comprehensive search strategy including MeSh terms. Relevant MeSh terms were identified in an analysis of the MeSh term database of the National Library of Medicine [14]. Additional search terms were identified by screening the author-supplied keywords on PubMed to ensure that the latest articles which had not yet been indexed were also included. The wide scope of the review question and the previously experienced lack of published literature and evidence on the subject led us to search all fields of the database-entries, not only title and abstracts. In addition, we searched in common language to identify as many relevant papers as possible and especially publications not yet indexed. The search strategy included the primary search terms "telemedicine", "remote consultation", "oceans and seas", "naval medicine", "emergencies", "emergency medicine”, "emergency medical services", "rescue work", "first aid", "accidents", "oil and gas industry", "fossil fuels", and "oil and gas fields", as well as the keywords "telemedicine", "telehealth", "remote consultation", “teleconsultation", "offshore”, "oceans", "nautical medicine", "emergency", "emergency medicine”, "emergency medical service", "emergency health service", "emergency care", "rescue work", "first aid", "accidents", "petroleum industry", "fossil fuel", and "oil and gas fields". Key words concerning the oil and gas industry were deliberately included in the search because this industry has been the main drive for innovation on offshore installations over the past decades.

Additionally, a search for grey literature was carried out using the main search terms "telemedicine", "offshore wind", "offshore oil and gas" and "quality". For this search, Google Scholar was used in private mode to ensure replicability of result. 
Furthermore, the reference lists of included publications were cross-checked for potentially relevant articles.

The complete search strategy is available in the supplementary material (see Additional file 2).

The results of the searches were imported into the online review tool Covidence [15] which was used in the subsequent process.

\section{Screening procedure, inclusion and exclusion criteria}

After removal of duplicates, all publications were included in the subsequent review process. All titles and abstracts were screened for potential relevancy. Potentially relevant papers were assessed for eligibility based on inclusion and exclusion criteria following the PCCapproach (population, concept, context) [16]. The PCC elements are listed in Table 1 . The screening process has been conducted by two reviewers (AW, MH) separately. Consensus meetings were held with an experienced third reviewer (JS) as needed.

Publications were included if they met the following criteria:

- Focus on medical expert users of telemedicine

- QIs describing telemedical care or items that could be used as such QIs were identifiable

- Operation of telemedicine in offshore wind or offshore oil and gas industry

Publications were excluded for the following reasons only:

- No focus on telemedicine

- No focus on offshore installations

- No full text available

- Not addressing QIs or items that QIs could be derived from

There were no restrictions regarding language and type of study. We included all relevant publications regardless of date of publication.

All publications included in this review were read systematically, and relevant information was extracted. Findings were classified according to the dimensions of quality established by Donabedian [11].

Table 1 PCC elements for inclusion and exclusion criteria

\begin{tabular}{ll}
\hline PCC-element & Definition \\
\hline Population & Medical expert users of telemedicine \\
concept & $\begin{array}{l}\text { Qls describing the quality of telemedical care } \\
\text { published items, that could be the basis for Qls } \\
\text { offshore oil and gas or offshore wind industry }\end{array}$ \\
\hline
\end{tabular}

\section{Results}

Altogether 14,012 publications were identified. The search for grey literature yielded 352 papers.

After removal of duplicates, a total of 10,236 publications were included in the screening process. Out of these, 49 potentially relevant papers were assessed for eligibility based on inclusion and exclusion criteria.No explicit QIs regarding the quality of telemedical care offshore were found.However, 15 publications were included in this Scoping Review as they contained findings, from which QIs could be derived.

The identification and selection process is visualized in the PRISMA Flow Chart in Fig. 1.

The 15 publications included eight journal articles $[3,4$, 17-22], five conference reports [6, 23-26], one doctoral thesis [27], and one chapter of a book [28]. Table 2 shows a summary of the publications.

The types of publication were heterogenous, varying from prospective studies [18, 20, 22, 27], qualitative analyses [6,21], a literature review [3], and a theoretical underpinning [17] to retrospective experience reports, partly with no scientific data base [4, 19, 23-26, 28]. Seven articles addressed quality of telemedical care offshore [6, 20-24, 26], five articles covered areas relevant for the topic scientifically [17-19, 25, 27], and three articles discussed the topic without any data base $[3,4,28]$. Seven of the fifteen publications were identified through grey literature research and reference cross check instead of medical database inquiry $[19,21,23-26,28]$.

\section{Structure quality}

Ten of the fifteen publications dealt with topics relevant for structure quality such as technical equipment, coordination structures, and best approaches for the development of quality of telemedical care offshore $[3,4,6,19$, 21-25, 28].

Five publications dealt with technical equipment for telemedicine. Five of them stressed the importance of reliably sharing real time objective information via audio/ video link, phone, fax, or email $[3,6,19,21,24]$, and one described the technology used [28]. Three publications favored an easy to use "plug-and-play" - or "one button push" solution over complex medical and communication equipment. Complex equipment may lead to a distraction from the patient and may therefore negatively affect treatment [22, 24, 28].

\section{Process quality}

Ten of the fifteen articles covered issues concerning process quality, such as the importance of communication processes and human resources that ensure quality [3, 4, 17-21, 24-26]. Two articles discussed qualifications of both, the teleconsultant physicians onshore and the 


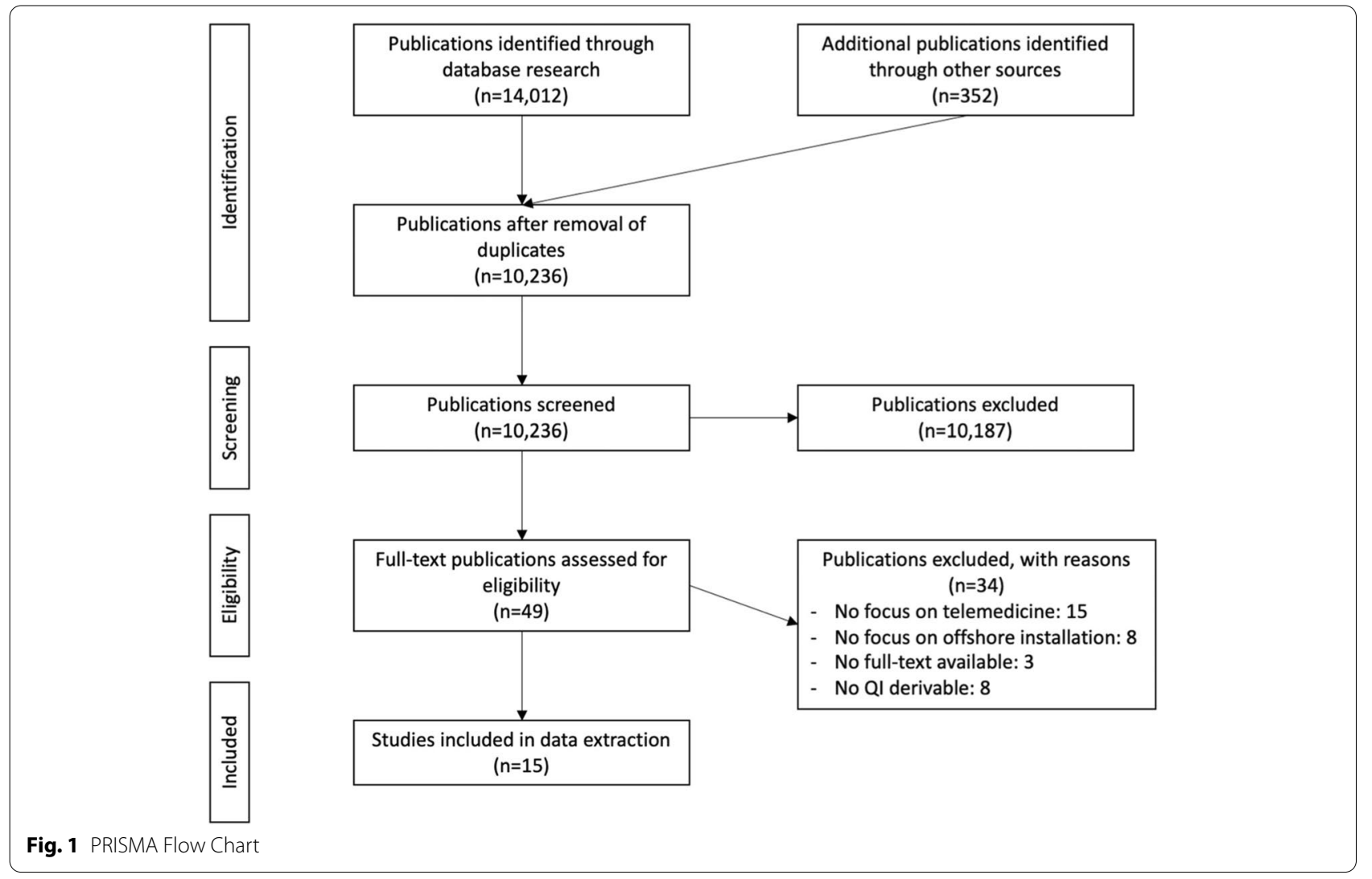

medical personnel offshore [4, 25]. Two other articles dealt with the effects of contextualized simulation training for medical personnel offshore $[17,18]$. One article stressed the importance of adjusting to end-user acceptance when implementing telemedical solutions [22].

\section{Outcome quality}

Only one of the fourteen publications addressed outcome quality. The authors reported that expert ECG interpretation onshore and advice on the management of chest pain offshore affects the rate of evacuation [19].

In Table 3, findings, from which QIs could be derived are summarized.

\section{Discussion}

We could not identify any explicit QIs for telemedicine on offshore structures in the reviewed literature. However, there were relevant findings from which 24 possible future QIs could be derived.

Six out of the fifteen publications identified were case or experience reports $[4,23-26,28]$. Therefore, studies resulting in a higher level of evidence are needed.
Minimum standards in health care legislation for offshore settings vary greatly and lack international standardization [3, 4]. Oil and Gas UK (OGUK) and the International Petroleum Industry Environmental Conservation Association (IPIECA) both have issued guidelines on medical equipment and facilities for their offshore installations $[5,29,30]$ but no specific recommendations for the use of telemedicine could be identified. The general approach and standardization for health and safety in the offshore wind industry should be systematic and has not yet reached the same level as in the offshore oil and gas industry [31]. The European Union has announced to standardize and publish health, safety and environment recommendations for the industry in the future [32] but so far, no official plans for the implementation of QIs have been published.

According to one author, there are several possible designated uses for telemedicine offshore [3]:

- First medical opinion: to interpret medical reports, e. g. X-ray or electrocardiogram (ECG).

- Second medical opinion: to define whether the case is an emergency or to evaluate the level of urgency 


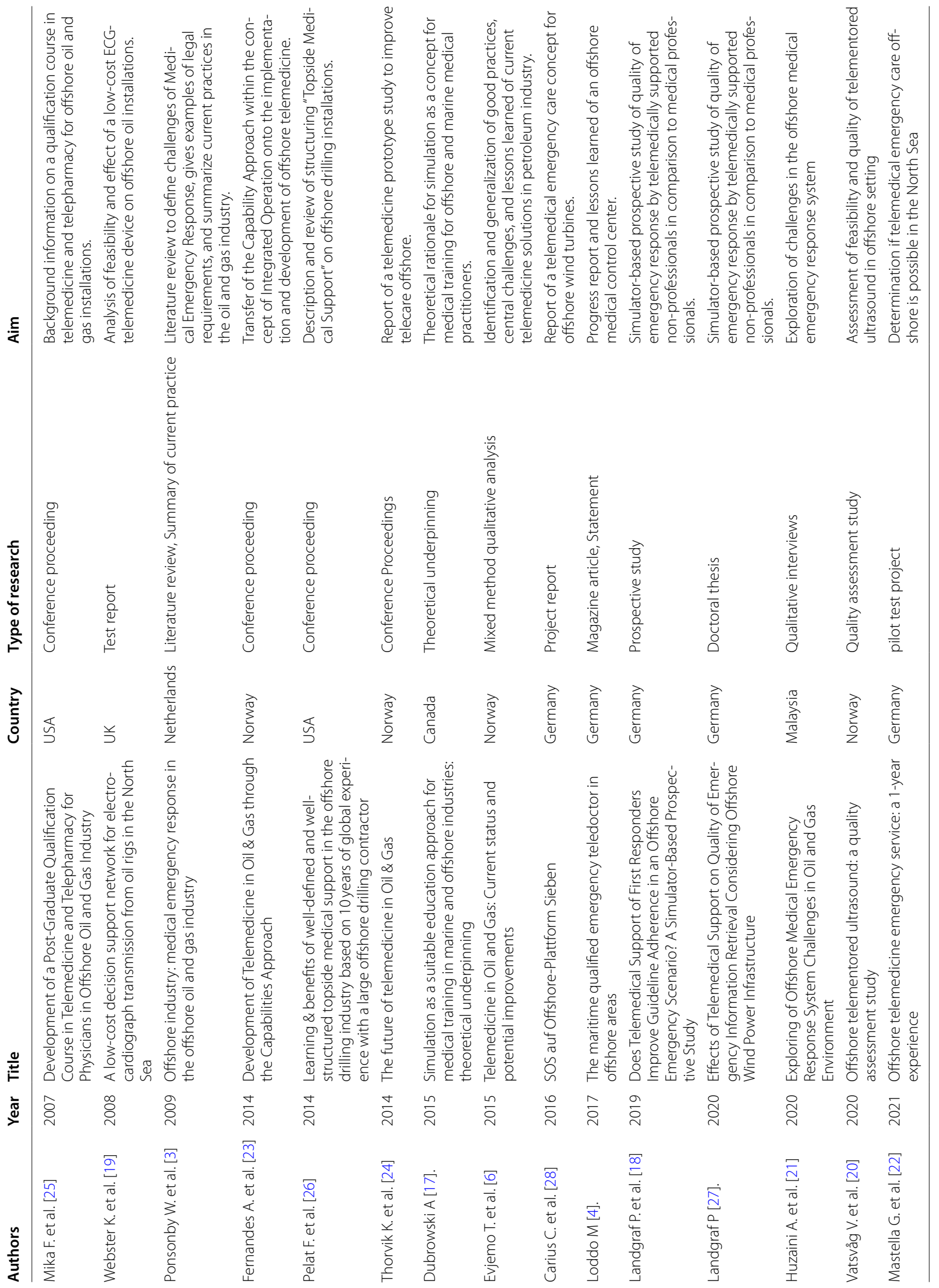




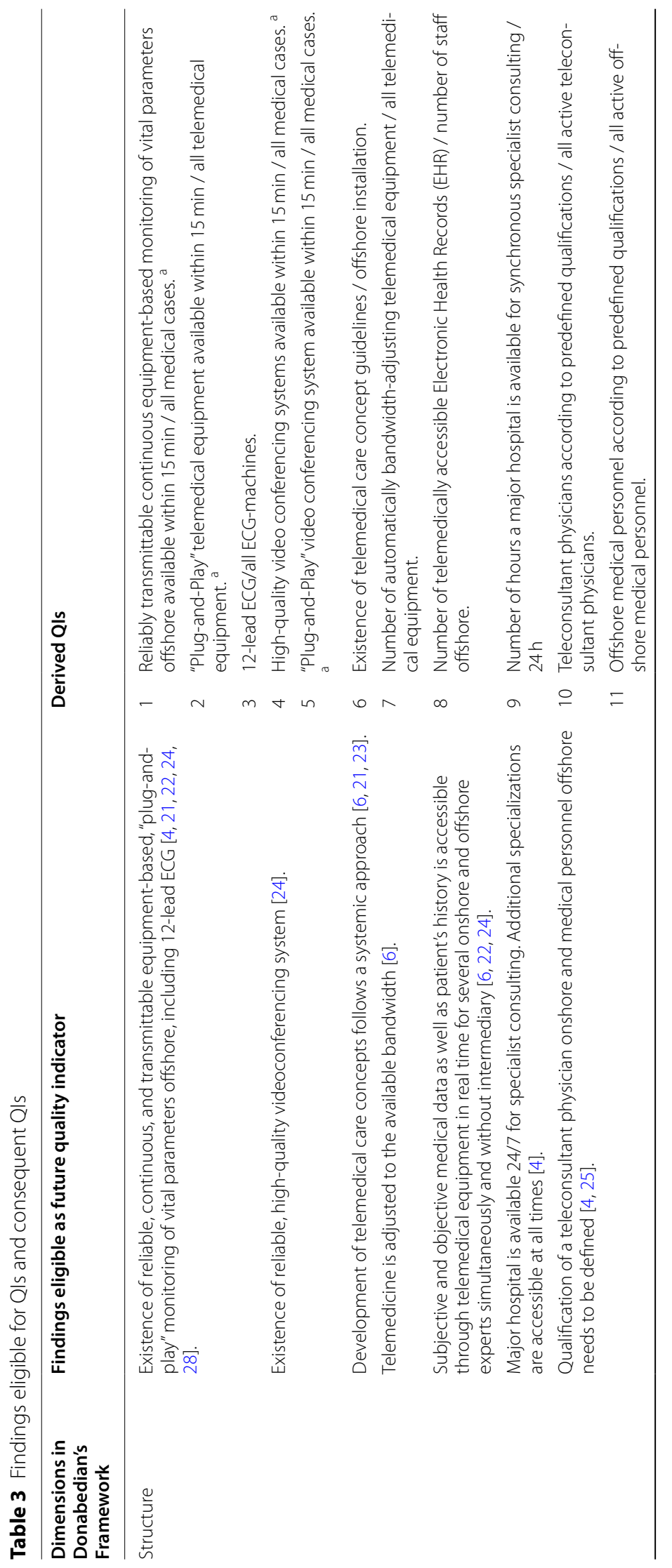




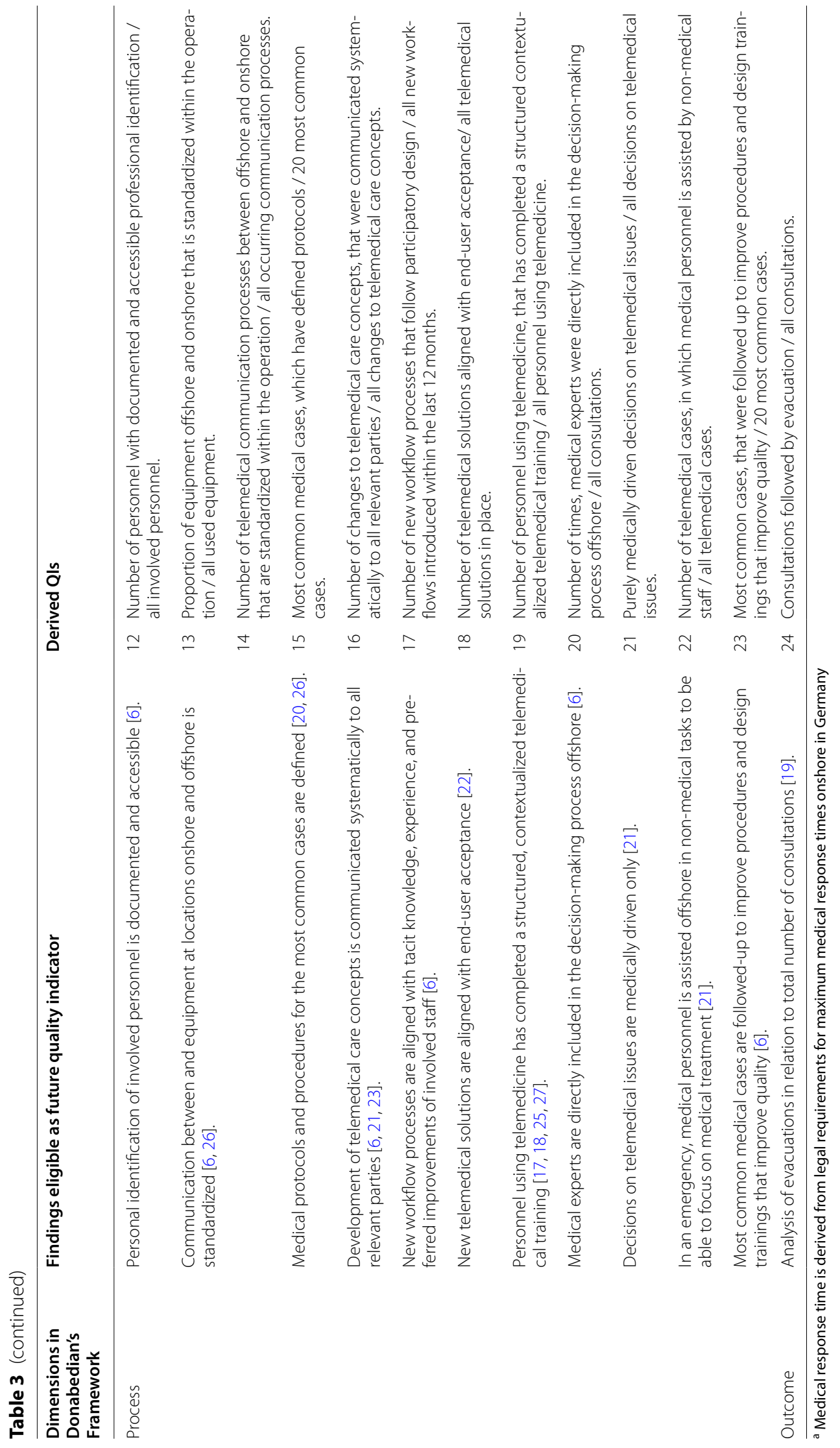


and the need for evacuation or for advice regarding the treatment before and during evacuation.

- Shared clinical management: management of patients with a temporary diagnosis or of complex cases by a "coordination unit" located at a specialist referral center assures a "single case - single connection - multiple response" model.

- Management of chronic diseases offshore.

However, the designated use is not standardized within the industry and there is no exact definition in the analyzed literature.

QIs 12 to 15 aim to facilitate intuitive cooperation in varying scenarios where personnel is mostly unfamiliar, far away, and has different levels of expertise. Several authors reported that the standardization of equipment, communication, and procedures have proven to be effective in this facilitation $[24,26]$. While this finding seems plausible, no research regarding its necessity or the appropriate extent of standardization in the offshore telemedicine could be identified. The derived QIs therefore represent the beginning of a process that will result in more differentiated QIs. Future research steps should include development of more precise QIs, using e. g. the RAND UCLA Appropriateness method [33], including findings and QIs from this review. Resulting QIs should then be validated [34].

QI 10, 11, 15 and 23 aim to improve quality of medical care by ensuring that personnel is trained and procedures are fit for the medical cases that are to be expected. Their efficiency though is only as good as its underlying research. There was no close analysis identified regarding the spectrum of medical cases offshore. For the oil and gas industry, the most common reasons for consultation and evacuation have been analyzed $[8,35,36]$ but for the younger offshore wind industry, there is only little equivalent research available [37-39]. But situations may differ significantly. The spectrum of medical cases and the most common medical issues need to be further analyzed, and resulting appropriate qualifications need to be discussed and validated in future research. Two articles report on experiences with qualifications of consultant physician onshore and medical personnel offshore $[4,25]$. It seems necessary, that further structured research is undertaken about necessary qualifications. This research, however, must take into consideration an analysis of the spectrum of medical cases and the most common medical issues that involved personnel is confronted with. Resulting qualifications then should be transferred into a curriculum and be validated.

None of the findings identified in this review have dealt with the needs or the experience of the patient. Future research on telemedical care offshore needs to include this aspect as well, and resulting QIs need to be included in a set of QIs.

Findings from this review may be relevant for other areas of use of telemedicine too. E. g. QIs 1, 2 and 4-8 aim to promote a reliable connection, with intuitive equipment and a smooth process of consultation. QIs 9-11, 15, 19 and 20 aim to measure determinants of quality of the telemedical consultation itself and QIs 16, 17 and 23 aim to measure determinants of its improvement. This could be desirable for other scenarios as well. The defining aspects of QIs could, to some extent, be applicable. Therefore, the derived QIs may very well be not only the starting point of development of QIs for offshore telemedical care but may also feed into the definition and implementation of QIs for other scenarios in which medical personnel seeks senior medical expertise via synchronous virtual consultation.

\section{Limitations}

Our Scoping Review may be limited due to publications we could not identify because they are listed in other databases than the ones analyzed. Seven out of the fourteen publications included in the review were found in the grey literature search via Google Scholar and the reference cross check $[19,21,23-26,28]$ and not in the medical databases that we searched in. Researchers in the area of quality improvement of telemedical care offshore may not be medically associated or may publish in other databases than medical researchers.

Findings that QIs could be derived from mainly originate from literature concerning the offshore oil and gas industry. Several articles have been published or financed by oil and gas companies, their employees, or associated societies, so there may be a bias in findings [3, 23-26]. Some findings originate from authors with business interests in the field so their findings may be biased as well [4].

Situations offshore may differ significantly. While the offshore oil and gas industry operates in stationary and large groups of up to several hundred people, offshore wind workers are sometimes deployed in flexible groups of three workers only. The field of telemedicine offshore therefore needs to be differentiated, principles of operation and quality are only partially transferable from one scenario to another $[4,40,41]$.

Fast-developing technology may also lead to outdated findings that need to be evaluated carefully. Some articles report technical requirements that are already rather outdated compared to the medical and technical equipment used nowadays on ships and offshore installations, e. g. in the German Bight [3, 19]. The findings of this review are not intended to be generalized to the whole 
field of telemedicine, rather, they should be an impetus to address the issue of quality of telemedical care more firmly.

\section{Conclusion}

The quality of telemedical care offshore is mainly discussed without a solid data base in scientific publications, and no set of QIs or single QIs have been published yet. Overall, there is little evidence available and more research, using advanced methods, needs to be done. QIs need to be developed, validated, and evaluated. This review provides a first set of 24 QIs to start this process. These QIs may also be a starting point for the development of QIs in other areas of use of telemedicine.

\section{Abbreviations}

ECG: Electrocardiogram; EHR: Electronic Health Record; IPIECA: International Petroleum Industry Environmental Conservation Association; OGUK: Oil and Gas UK; QI: Quality indicator; UK: United Kingdom.

\section{Supplementary Information}

The online version contains supplementary material available at https://doi. org/10.1186/s12913-021-07303-5.

Additional file 1. Preferred Reporting Items for Systematic reviews and Meta-Analyses extension for Scoping Reviews (PRISMA-SCR) Checklist.

Additional file 2. Complete search strategy.

\section{Acknowledgements}

Not applicable.

\section{Authors' contributions}

$\mathrm{MH}$ conducted the database search and the search in grey literature, screened the search results, extracted the data, and drafted the manuscript. AW conducted the database search and the search in grey literature, screened the search results, and contributed to the data extraction as well as in drafting the manuscript. JS developed the research question, coordinated as a senior all steps of the study, contributed to the data extraction as well in drafting the manuscript. All authors read and approved the final manuscript.

\section{Funding}

This research received no specific grant from any funding agency in the public, commercial or not-for-profit sector. It was funded by the resources of the Institute for Family Medicine, University Medical Center Schleswig-Holstein, Campus Lübeck, Ratzeburger Allee 160, 23562 Lübeck, Germany. Open Access funding enabled and organized by Projekt DEAL.

\section{Availability of data and materials}

All data generated or analysed during this study are included in this published article and its supplementary information files.

\section{Declarations}

Ethics approval and consent to participate Not applicable.

\section{Consent for publication}

Not applicable.

\section{Competing interests}

The authors declare that they have no competing interest.
Received: 28 September 2021 Accepted: 11 November 2021

Published: 2 December 2021

\section{References}

1. Mair F, Fraser S, Ferguson J, Webster K. Telemedicine via satellite to support offshore oil platforms. J Telemed Telecare. 2008;14(3):129-31.

2. UK Oil and Gas Industry Association. OGUK workforce report 2019. 2019. Available from: https://oilandgasuk.cld.bz/Workforce-Report-2019/12/. Accessed 28 Sep 2021.

3. Ponsonby W, Mika F, Irons G. Offshore industry: medical emergency response in the offshore oil and gas industry. Occup Med (Lond). 2009;59(5):298-303

4. Loddo M. Der maritime Telenotarzt im Offshorebereich. Flugmedizin Tropenmedizin Reisemedizin. 2017;24(02):67-72.

5. International Association of Oil and Gas Producers. Health management in the oil and gas industry; 2019. p. 44. Available from: https://32zn5 6499nov99m251h4e9t8-wpengine.netdna-ssl.com/bookstore/wp-conte nt/uploads/sites/2/woocommerce_uploads/2020/03/343-Exec-Summa ry.pdf. Accessed 28 Sep 2021

6. Evjemo TE, Reegard K, Fernandes A, Reegård K, Fernandes A. Telemedicine in oil and gas: current status and potential improvements. Ahram T, Karwowski W, Schmorrow D, editors. Proc Manufact. 2015;3(2351):1289-96.

7. Flesche CW, Jalowy A, Inselmann G. Telemedizin in der Hochseeschifffahrt - Hightech aus Tradition. Med Klin. 2004;99(3):163-8. Available from: https://doi.org/10.1007/s00063-004-1026-5.

8. Thibodaux DP, Bourgeois RM, Loeppke RR, Konicki DL, Hymel PA, Dreger M. Medical evacuations from oil rigs off the gulf coast of the United States from 2008 to 2012: reasons and cost implications. J Occup Environ Med. 2014;56(7):681-5.

9. Barnett ML, Ray KN, Souza J, Mehrotra A. Trends in telemedicine use in a large commercially insured population, 2005-2017. JAMA. 2018. https:// doi.org/10.1001/jama.2018.12354

10. Cresswell K, Sheikh A. Organizational issues in the implementation and adoption of health information technology innovations: an interpretative review. Int J Med Inform. 2013;82(5):e73-86.

11. Donabedian A. The quality of care: how can it be assessed? JAMA. 1988 https://doi.org/10.1001/jama.1988.03410120089033.

12. Mainz J. Defining and classifying clinical indicators for quality improvement. Int J Qual Heal Care. 2003;15(6):523-30.

13. Tricco AC, Lillie E, Zarin W, O'Brien KK, Colquhoun H, Levac D, et al. PRISMA extension for scoping reviews (PRISMA-SCR): checklist and explanation. Ann Intern Med. 2018;169(7):467-73.

14. National Library of Medicine. Medical Subject Headings - Home Page. Available from: https://www.nlm.nih.gov/mesh/meshhome.html. Accessed 28 Sep 2021.

15. Veritas Health Innovation Ltd. covidence.org [Internet]. Available from: https://www.covidence.org. Accessed 28 Sep 2021.

16. The Joanna Briggs Insitute. The Joanna Briggs institute reviewers' manual 2015: methodology for JBI scoping reviews. The Joanna Briggs institute reviewers' manual 2015: methodology for JBI scoping reviews. Adelaide: Joanne Briggs Institute; 2015. p. 1-24.

17. Dubrowski A. Simulation as a suitable education approach for medical training in marine and off-shore industries: theoretical underpinning. Int Marit Health. 2015;66(3):164-7.

18. Landgraf P, Spies C, Lawatscheck R, Luz M, Wernecke K-D, Schröder T. Does Telemedical support of first responders improve guideline adherence in an offshore emergency scenario? A simulator-based prospective study. BMJ Open. 2019 Aug;9(8):e027563.

19. Webster K, Fraser S, Mair F, Ferguson J. A low-cost decision support network for electrocardiograph transmission from oil rigs in the North Sea. J Telemed Telecare. 2008;14(3):162-4.

20. Vatsvåg V, Todnem K, Næsheim T, Cathcart J, Kerr D, Oveland NP. Offshore telementored ultrasound: a quality assessment study. Ultrasound J. 2020. https://doi.org/10.1186/s13089-020-00180-9.

21. Bin HAS, Mohammad R, Othman N, A.kadir Z. Exploring of offshore medical emergency response system challenges in oil and gas environment. J Environ Treat Tech. 2020;8(1):364-73. 
22. Mastella G, Darstein L, Raufhake C, Schneider V, Corletto A, Buiatti A, et al. Offshore telemedicine emergency service: a 1-year experience. J Public Heal. 2021. https://doi.org/10.1007/s10389-021-01511-3.

23. Fernandes A, Reegård K, Drøivoldsmo A, Simensen JE, Rindahl G. Development of telemedicine in oil \& gas through the capabilities approach. 2014. Available from: https://www.researchgate.net/publication/27148 5380_Development_of_telemedicine_in_oil_gas_through_the_capab ilities_approach. Accessed 28 Sep 2021.

24. Thorvik K, Nystad A, Skogås JG, Fernandes A, Reegard K, Simensen $\mathrm{JE}$, et al. The future of telemedicine in O\&G. In: Society of Petroleum Engineers - SPE intelligent energy international 2014. Utrecht: Society of Petroleum Engineers; 2014. p. 259-66. Available from: https://www. onepetro.org/conference-paper/SPE-167841-MS. Accessed 28 Sep 2021.

25. Mika F, Amenta F, De Sanctis S, Nicosia V, Tayebati K, Tomassi D. Development of a post-graduate qualification course in telemedicine and telepharmacy for physicians in offshore oil and gas industry. In: Society of Petroleum Engineers - Asia Pacific Health, Safety, Security and Environment Conference and Exhibition. Bangkok: Society of Petroleum Engineers; 2007. Available from: https://onepetro.org/SPEAPHS/proce edings-abstract/07APHS/All-07APHS/SPE-108864-MS/142676. Accessed 28 Sep 2021

26. Pelat F, Awotula P. Learning \& benefits of well-defined and well-structured topside medical support in the offshore drilling industry based on 10 years of global experience with a large offshore drilling contractor. In: Society of Petroleum Engineers - SPE International Conference on Health, Safety and Environment 2014: The Journey Continues. 2014. p. 883-891. Available from: https://onepetro.org/SPEHSE/proceedings-abstract/ 14HSE/3-14HSE/D031S054R003/210790. Accessed s8 Sep 2021.

27. Landgraf P. Effects of telemedical support on quality of emergency information retrieval considering offshore wind power infrastructure. Charité Berlin; 2020. Available from: https://refubium.fu-berlin.de/bitstream/ handle/fub188/27220/Landgraf_Effects_refubium.pdf?sequence=3\&isAll owed $=y$. Accessed 28 Sep 2021

28. Carius C, Jacob C, Schultz M. SOS auf Offshore-Plattform Sieben. In: Meer - Wind - Strom. Wiesbaden: Durstewitz, Michael ; Lange, Bernhard; 2016. p. 255-60. Available from: https://www.springer.com/de/book/97836 58097820. Accessed 28 Sep 2021.

29. UK Oil and Gas Industry Association. Medications \& Medical Equipment on offshore installations - guidelines. United Kingdom; 2019. Available from: https://oguk.org.uk/product/medications-and-medical-equipmentfor-offshore-installations-guidelines/. Accessed 28 Sep 2021.

30. International Petroleum Industry Environmental Conservation Association (IPIECA). Managing health for field operations in oil and gas. 2011. Available from: https://www.internationalsosfoundation.org/-/media/ international-sos-foundation/files/resources/international/oil-and-gas/ managing-health-for-field-operations-in-oil-and-gas-activities.pdf?la=en, Accessed 28 Sep 2021.

31. Lloyd PO. Health and safety of offshore wind farms. In: Offshore wind farms: technologies, design and operation: Elsevier; 2016. p. 573-87. Available from:. https://doi.org/10.1016/B978-0-08-100779-2.00019-2.

32. European Commission. Roadmap of offshore renewable energy strategy. 2020.

33. Fitch K, Bernstein SJ, Aguilar MD, Burnand B, LaCalle JR, Lázaro P, et al. The RAND/UCLA Appropriateness Method User's Manual. Available from: https://www.rand.org/content/dam/rand/pubs/monograph_reports/ 2011/MR1269.pdf. Accessed 28 Sep 2021.

34. Grol R, Wensing M. PATIENTS EVALUATE GENERAL / FAMILY PRACTICE the EUROPEP instrument; 2000. p. 1-71. Available from: https://equip.wonca europe.org/sites/equip/files/documents/publications/resources/grolw ensing2000theeuropepinstrumentequipwonca.pdf. Accessed $28 \mathrm{Sep}$ 2021

35. Norman JN, Ballantine BN, Brebner JA, Brown B, Gauld SJ, Mawdsley $\mathrm{J}$, et al. Medical evacuations from offshore structures. Br I Ind Med. 1988:45(9):619-23.

36. Toner S, Andrée Wiltens DH, Berg J, Williams H, Klein S, Marshall S, et al. Medical evacuations in the oil and gas industry: A retrospective review with implications for future evacuation and preventative strategies. J Travel Med. 2017;24(3):1-7.

37. Stuhr M, Dethleff D, Weinrich N, Nielsen M, Hory D, Seide K, et al. Vorläufige Auswertung: Medizinische Ereignisse in Offshore-Windparks - Erste
Informationen zu Unfallverletzungen und Erkrankungen. Flugmedizin Tropenmedizin Reisemedizin. 2015;22(01):14-9.

38. Dambach K, Adams HA. Medizinische Ereignisse in Offshore-Windparks Art, Inzidenz und medizinische Versorgung. Anästhesiol Intensivmed. 2015:56:119-24.

39. Dethleff D, Weinrich N, Kowald B, Hory D, Franz R, Nielsen MV, et al. Air medical evacuations from the German North Sea wind farm bard offshore 1: traumatic injuries, acute diseases, and rescue process times (2011-2013). Air Med J. 2016. https://doi.org/10.1016/.amj.2016.02.002.

40. Stuhr M, Dethleff D, Weinrich N, Nielsen M, Hory D, Kowald B, et al. Notfallmedizinische Versorgung in Offshore-Windparks: Neue Herausforderungen in der deutschen Nord- und Ostsee. Anaesthesist. 2016;65(5):369-79.

41. Puskeppeleit M. Medizin im Offshore Bereich. In: Ottomann C, Seidenstücker K-H, editors. Maritime Medizin - Praxiswissen für Schiffsärzte und Ärzte im Offshore-Bereich. Berlin Heidelberg: Springer Berlin Heidelberg; 2015. p. 35-47. Available from: https://www.springer.com/de/book/ 9783642554377. Accessed 28 Sep 2021.

\section{Publisher's Note}

Springer Nature remains neutral with regard to jurisdictional claims in published maps and institutional affiliations.
Ready to submit your research? Choose BMC and benefit from:

- fast, convenient online submission

- thorough peer review by experienced researchers in your field

- rapid publication on acceptance

- support for research data, including large and complex data types

- gold Open Access which fosters wider collaboration and increased citations

- maximum visibility for your research: over $100 \mathrm{M}$ website views per year

At BMC, research is always in progress.

Learn more biomedcentral.com/submissions 